\title{
Design and Implementation of MATLAB-Simulink Based Solar Cell Model- ing and PV System Design Exercises for Advanced Student Learning
}

\section{Dr. Sandip Das, Kennesaw State University}

Sandip Das is an Assistant Professor in the Department of Electrical Engineering at Kennesaw State University. Dr. Das received his Ph.D. and M.E. in Electrical Engineering from University of South Carolina, Columbia and earned his B.E. in Electrical Engineering from Indian Institute of Engineering Science and Technology (IIEST, Shibpur, India). He is an expert in the field of solar photovoltaics and developed undergraduate and graduate-level courses in solar power and advanced photovoltaics at Kennesaw State University. His current research interests include third generation solar cells for building-integrated photovoltaics, semiconductor thin-films and nanocrystals for optoelectronic devices, mixed-signal electronics for instrumentation and development of technology enhanced teaching tools and pedagogical framework for improved engineering education. He has published more than 20 technical research articles in international journals and conferences. His innovative teaching and research programs have been supported by the Center for Excellence in Teaching and Learning (CETL) at Kennesaw State University and the U.S. Environmental Protection Agency (EPA). 


\title{
Design and Implementation of MATLAB-Simulink Based Solar Cell Modeling and PV System Design Exercises for Advanced Student Learning
}

\begin{abstract}
The solar photovoltaics (PV) industry has created the fastest growing job market in the US demanding highly skilled engineers. Modeling and simulation of solar cells and design of solar photovoltaic systems are highly marketable skills desired by the industry. Simulation tools provide a robust platform to build models and help students to analyze the behavior and performance of the devices and systems. This paper discusses on the MATLAB-Simulink based simulation exercises integrated within a renewable energy course in undergraduate Electrical Engineering curriculum. The simulation exercises include building single diode equivalent circuit model of a solar cell and analysis of the simulated current-voltage (I-V) and power-voltage (P-V) curves using MATLAB scripts and Simulink graphical simulation environment. Students then study the effect of solar irradiance, temperature, series and shunt resistances on the resulting photovoltaic parameters, such as open-circuit voltage, short-circuit current, fill factor, and efficiency of the cell. By interconnecting multiple cells in series, students designed PV modules. Finally, students studied the effect of partial shading in series connected modules and learned the utility of bypass diodes. Successful integration of the simulation exercises could substantially help to optimize the student learning outcome. The impact of the simulation exercises and learning outcome were measured by pre- and post-exercise tests and student perceptions via student feedback.
\end{abstract}

\section{Introduction:}

Solar power offers infinite source of renewable energy and is predicted to meet a significant portion of our energy demand in the near future. The PV industry has been growing at a very fast pace around the world and is predicted to reach TW-scale generation by $2050^{1-4}$. Such rapid growth has created new job opportunities. According to the solar job census 2016, the PV industry in the US employed more than 260 thousand workers. This number is predicted to increase in the coming decades. Therefore, it is important to create skilled engineers to support this growing industry by providing advanced PV education at the undergraduate level.

Simulation softwares are excellent teaching tools which have the potential to aid in student learning, specifically to communicate advanced complex ideas visually. In addition, simulation skills are highly marketable in the industry and could potentially improve the job prospect of students. Incorporating comprehensive simulation exercises into a solar power or renewable energy course is the key step toward developing an advanced education program in this field. MATLAB-Simulink provides a strong simulation platform for electronic circuits and power systems, and has become one of the most widely used simulation software in the industry and academia. This paper discusses on the design, development and implementation of comprehensive MATLAB-Simulink based exercises and reports on the direct and passive assessment results on student learning outcomes in an electrical engineering course 'Solar Power and Renewable Energy'. The developed MATLAB-Simulink exercises challenge students in various ways to build the necessary skillset and knowledge to perform even more complex simulations in the future. The simulation assignments contributed toward $10 \%$ of the final grade. The following sections discuss 
about the exercises with simulation results to provide a detailed understanding about the problems assigned in this study and present direct and passive assessment method along with the measured learning outcomes.

\section{Description of Simulation Exercises:}

The entire set of exercises were divided into 5 segments, or 5 'Tasks'. Task 1 included an assignment of reading four different solar cell datasheets from various manufacturers. All other tasks (Task 2 - Task 5) included specific simulation exercises. Learning objectives for each task are summarized in the flowchart as shown in Fig. 1.
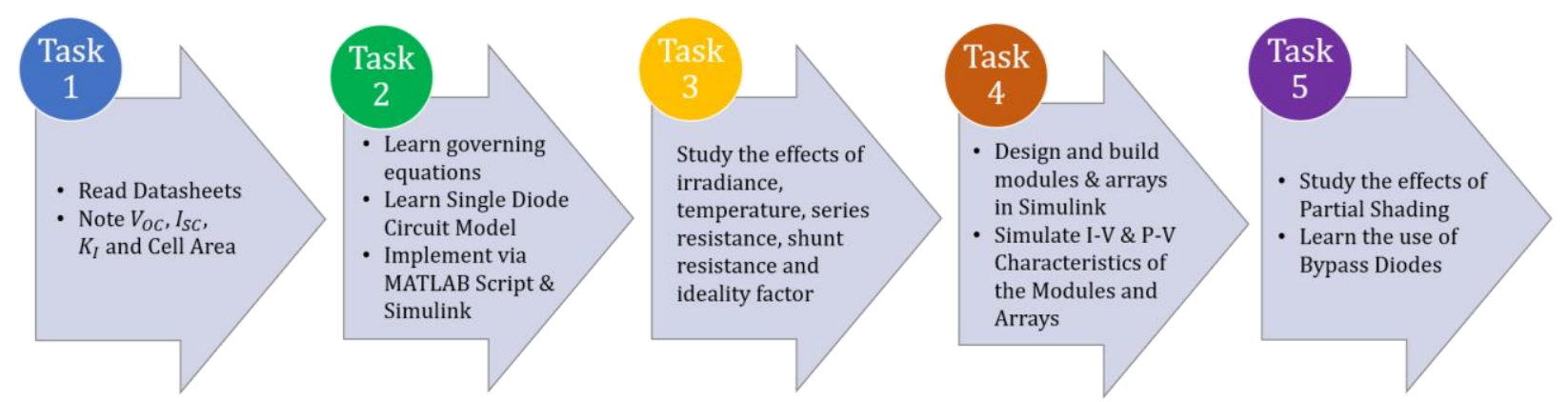

Figure 1. Flowchart showing the assignment Tasks and learning objectives for each task.

\subsection{Theory and Background - The Single Diode Model:}

A solar cell can be electrically modeled as shown in Fig. 2. It comprises of a DC current source $\left(I_{p h}\right)$, one diode $(D)$, a shunt resistance $\left(R_{s h}\right)$, and a series resistance $\left(R_{s}\right)$. The DC current source is directly proportional to the incident light intensity.

The relationship of the current and voltage at the output terminals of the cell is given by the

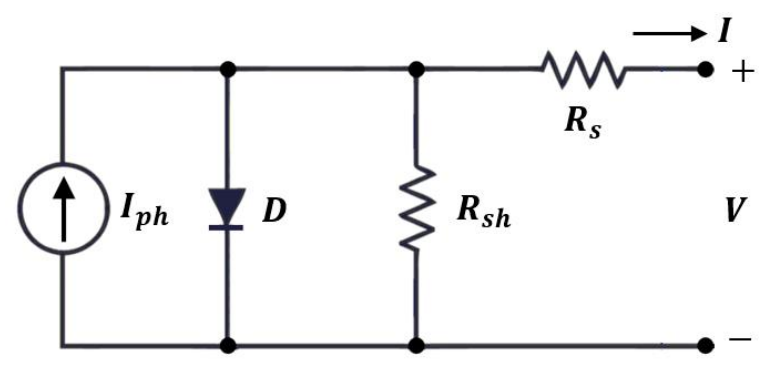

Figure 2. Single diode model of a solar cell. following equation ${ }^{5,6}$ :

$$
I=I_{p h}-I_{s}\left[\exp \left(\frac{V+I R_{s}}{n V_{T}}\right)-1\right]-\left(\frac{V+I R_{s}}{R_{s h}}\right)
$$

Where, $I$ is the output current, $V$ is the voltage at the output terminals of the cell, $I_{p h}$ is the photocurrent, $I_{S}$ is the reverse saturation current, $q$ is the electronic charge $\left(1.602 \times 10^{-19} \mathrm{C}\right), n$ is the diode quality factor, and $V_{T}$ is the thermal voltage, which is equal to $25.7 \mathrm{mV}$ under the standard test condition (STC) which refers to a temperature of $25^{\circ} \mathrm{C}$ or $298 \mathrm{~K}$.

\subsection{Task 1 - Reading Datasheets:}

In Task 1, students were required to note down the manufacturer specified PV parameters from solar module datasheets, such as open-circuit voltage $\left(V_{O C}\right)$, short-circuit current $\left(I_{S C}\right)$, temperature 
co-efficient of short-circuit current $\left(K_{I}\right)$, and the cell area. This is an important step before the simulation models can be constructed. Only one solar cell's data (Q-Cells; Model: Q6LMXP3-G3, Power Class: 4.53) was used for modeling and simulation ${ }^{7}$. This cell had the following parameters: $V_{O C}=0.636 \mathrm{~V}, I_{S C}=9.15 \mathrm{~A}$, and $K_{I}=+4.575 \mathrm{~mA} / \mathrm{K}$, and cell area $=243.36 \mathrm{~cm}^{2}$.

\subsection{Task 2 - Building Solar Cell Model in MATLAB and Simulink:}

In Task 2, students built the single diode model using MATLAB script, as well as Simulink (using the built-in Simscape package). The Simulink model is shown in Fig. 3. A variable resistor is connected across the cell which is ramped from zero to a high value (around $100 \Omega$ ) to trace the I$\mathrm{V}$ and $\mathrm{P}-\mathrm{V}$ curves as simulation proceeds.

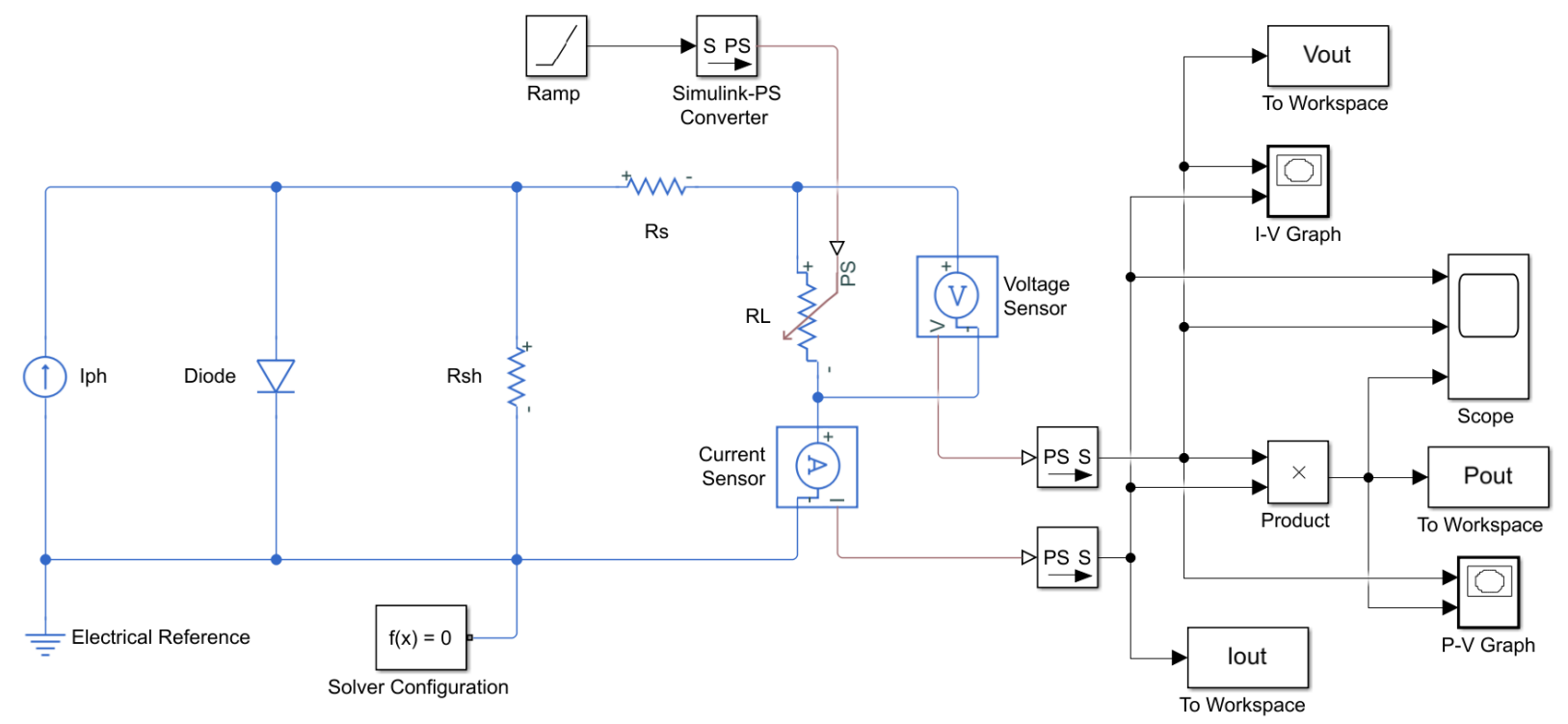

Figure 3. Simulink model of the solar cell to simulate the I-V and P-V curves.

The output current, voltage and power values are exported to the MATLAB workspace in the form of arrays using the "To workspace" Simulink blocks for further analysis and plots. Students were required to analyze the exported data and extract critical PV parameters, such as the maximum power $\left(P_{\max }\right)$, fill factor $(F F)$ and efficiency $(\eta)$.

\subsection{Task 3 - Studying the Effects of Irradiance, Temperature, $R_{S}, R_{S h}$ and $n$ :}

Task 3 was sub-divided into five parts to study the effects of - (i) Irradiance, (ii) Temperature, (iii) Series Resistance, (iv) Shunt Resistance and (v) Ideality Factor of the device. To perform Task 3, students were introduced to the following governing mathematical equations ${ }^{8,9}$ :

$$
\begin{aligned}
& I_{S(S T C)}=I_{S C(S T C)}\left[\exp \left(\frac{V_{O C}(S T C)}{n V_{T}}\right)-1\right]^{-1} \\
& I_{S}=I_{S(S T C)}\left(\frac{T}{T_{S T C}}\right)^{3} \exp \left[\frac{q E_{g}}{n k}\left(\frac{1}{T_{S T C}}-\frac{1}{T}\right)\right]
\end{aligned}
$$




$$
I_{p h}=\left(\frac{\text { Irradiance }}{1000}\right) \times\left[I_{S C(S T C)}+K_{I}\left(T-T_{S T C}\right)\right]
$$

Where, $I_{S(S T C)}$ is the reverse saturation current under STC; $I_{S C \text { (STC) }}$ is the short-circuit current under STC, which is $9.15 \mathrm{~A}$ as per the manufacturer's datasheet, $V_{O C}(S T C)$ is the open-circuit voltage under STC, which is equal to $0.636 \mathrm{~V}$. $n$ is the diode ideality factor, which is a measure of how closely the solar cell behave as an ideal diode under dark. For a device with ideal diode like behavior, $n=1$ and in real-life devices $n>1 . I_{S}$ is the calculated reverse saturation current for the chosen simulation temperature $T$ and $T_{S T C}$ refers to $25^{\circ} \mathrm{C}$ or $298 \mathrm{~K}$. $E_{g}$ is the bandgap energy of the semiconductor, for $\mathrm{Si}$, it is $1.1 \mathrm{eV}$ at STC. $k$ is the Boltzmann constant $\left(1.38 \times 10^{-23} \mathrm{~J} / \mathrm{K}\right)$ and $K_{I}$ is the temperature coefficient of short-circuit current, which is $+4.575 \mathrm{~mA} / \mathrm{K}$ for the chose cell.

To study the effect of irradiance, the illumination intensity was varied from $200 \mathrm{~W} / \mathrm{m}^{2}$ to 1000 $\mathrm{W} / \mathrm{m}^{2}$ with an increment of $200 \mathrm{~W} / \mathrm{m}^{2}$. The simulated I-V and P-V curves are shown in Fig. 4.
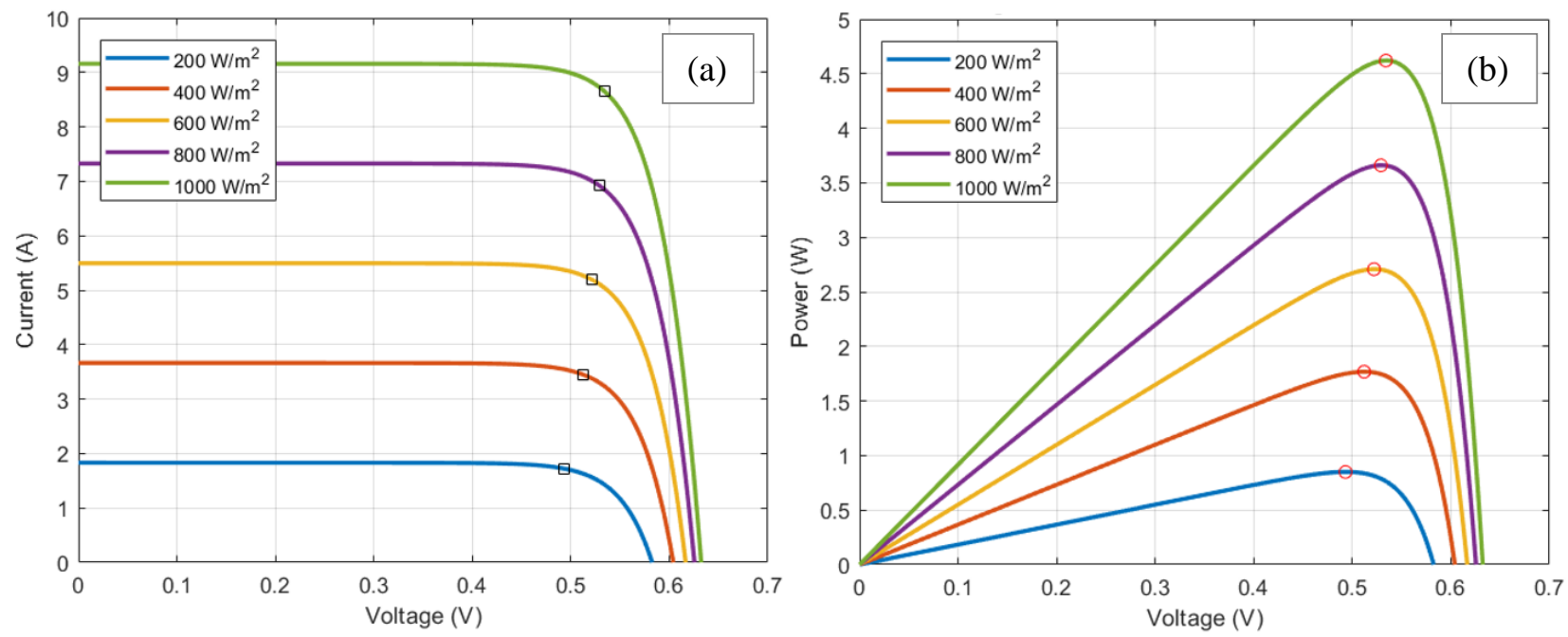

Figure 4. Simulated (a) I-V, and (b) P-V curves of the solar cell at varying illumination intensities.
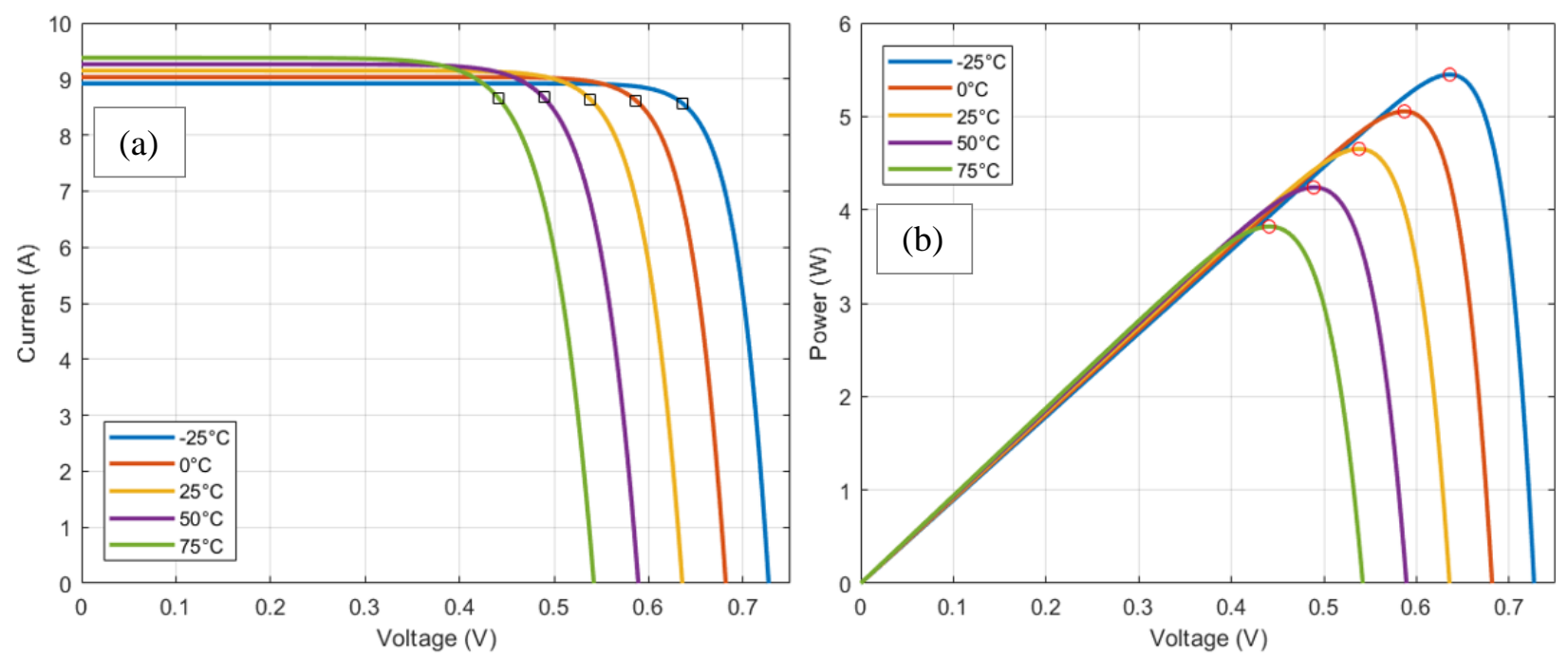

Figure 5. Simulated (a) I-V, and (b) P-V curves of the solar cell at varying temperatures. 
Effect of temperature was studied within a range from $-25^{\circ} \mathrm{C}$ to $75^{\circ} \mathrm{C}$ with an increment of $25^{\circ} \mathrm{C}$. The corresponding I-V and P-V curves are presented in Fig. 5. Series resistance was varied from $5 \mathrm{~m} \Omega$ to $45 \mathrm{~m} \Omega$ with an increment of $15 \mathrm{~m} \Omega$ and shunt resistance was varied from $100 \mathrm{~m} \Omega$ to 300 $\mathrm{m} \Omega$ with an increment of $50 \mathrm{~m} \Omega$. The resulting I-V characteristics are shown in Fig. 6(a) and 6(b), respectively. Ideality factor was varied from 1.0 to 3.0 with an increment of 0.5 . Fig. 7 shows the effect of ideality factor $(n)$ on the output characteristics. In addition to the simulation and plots, students were required to analyze each simulated curve and extract all PV parameters to fill up tables that summarizes the trends and behavior of various cell parameters $\left(V_{O C}, I_{S C}, F F\right.$, $P_{\max }$, and $\eta$ ) as a function of illumination intensity, temperature, ideality factor, series and shunt resistances.
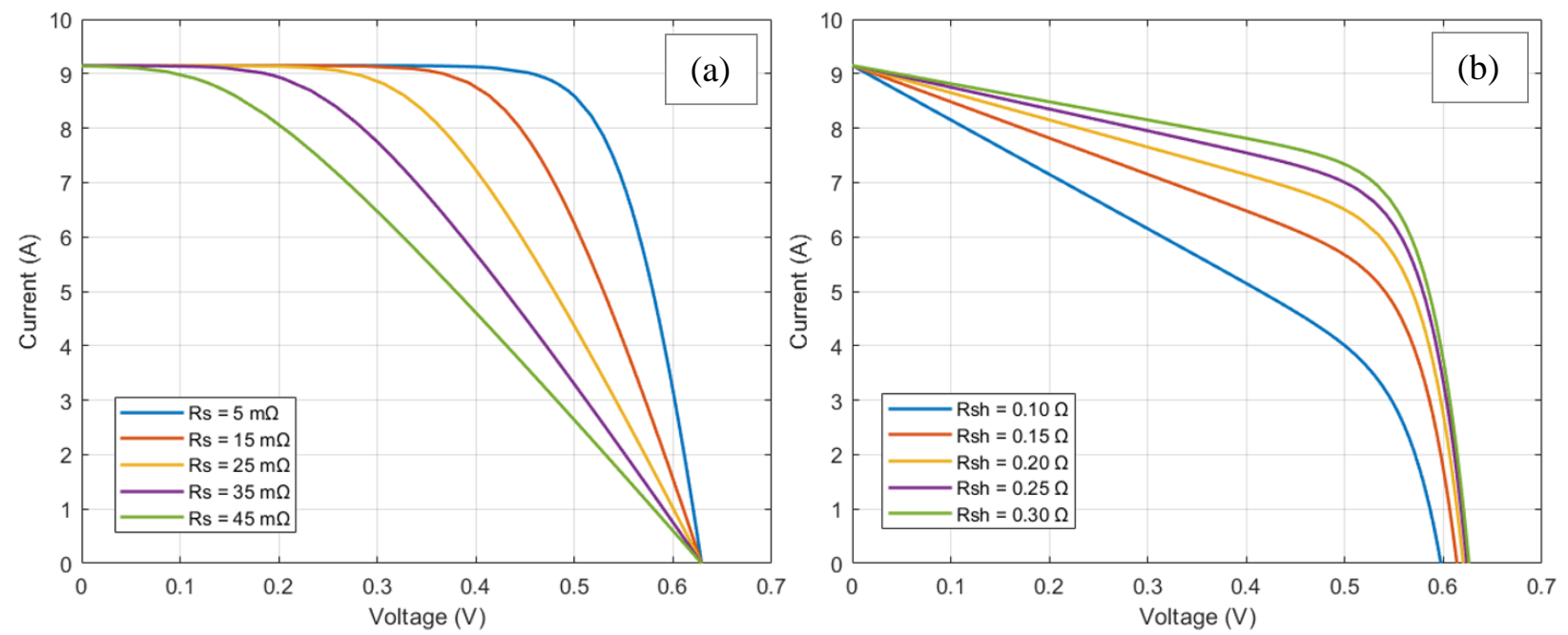

Figure 6. Simulated I-V characteristics at varying (a) series resistance and (b) shunt resistance.
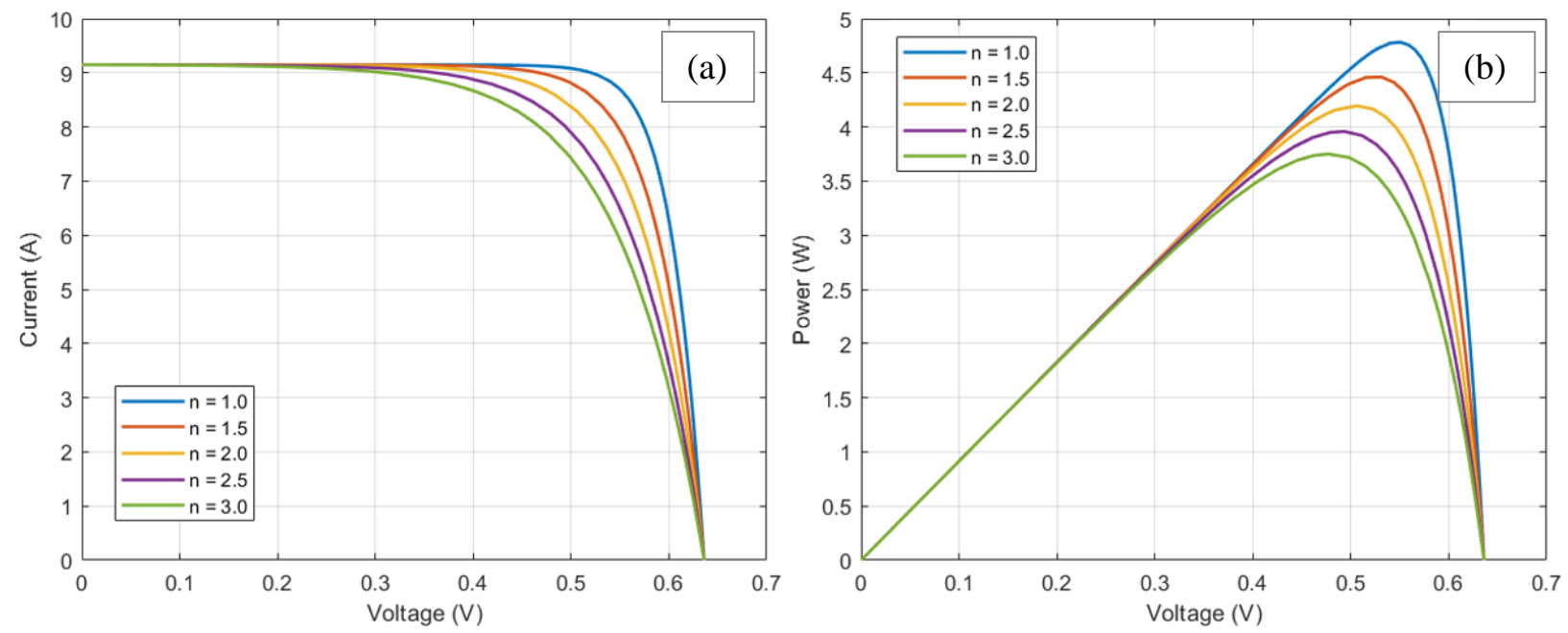

Figure 7. (a) I-V, and (b) P-V curves of the solar cell at varying ideality factors.

\subsection{Task 4 \& 5 - Modules, Arrays, Effects of Partial Shading and Bypass Diodes:}

In Task 4, students designed and built modules by interconnecting multiple solar cells in series. For this purpose, they were instructed to use Simulink's built-in solar cell block. After completing the interconnections, a sub-system was created by selecting the series connected string, followed 
by masking as a solar module (Fig 8(a) and 8(b)). An array was built with multiple of these modules connected in series and parallel. In Fig. 8(c), an example array of three series connected modules with different illumination intensities are shown illustrate the condition of partial shading 10. Students were asked to simulate the system with and without bypass diodes. Simulation fails to converge without bypass diodes. The resulting I-V and P-V curves for the array with bypass diodes is presented in Fig. 9.

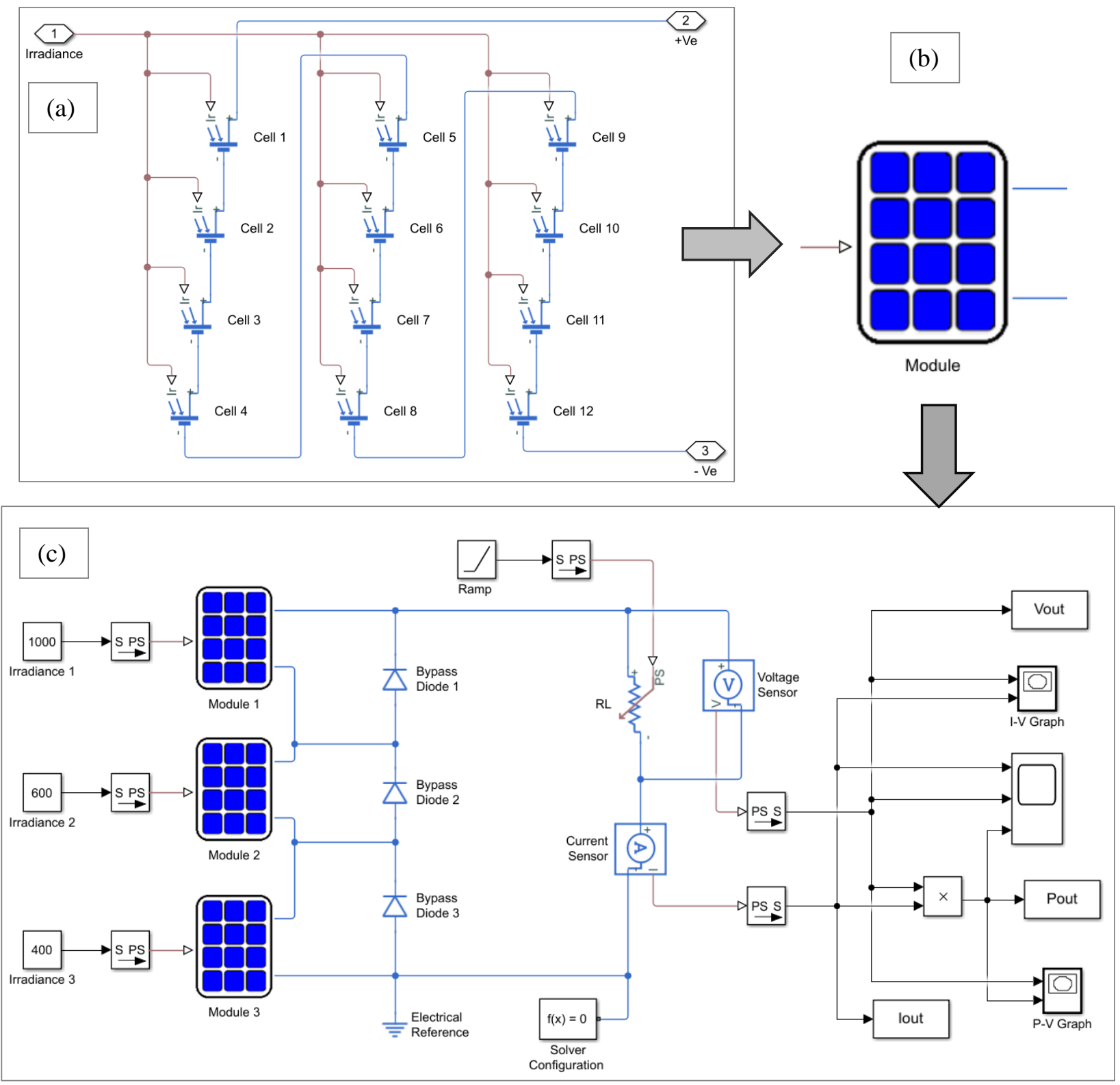

Figure 8. (a) Series connected solar cells (series string) forming a Simulink sub-system, (b) the subsystem is masked as a solar module and (c) three modules connected in series (including bypass diodes) to form an array. 


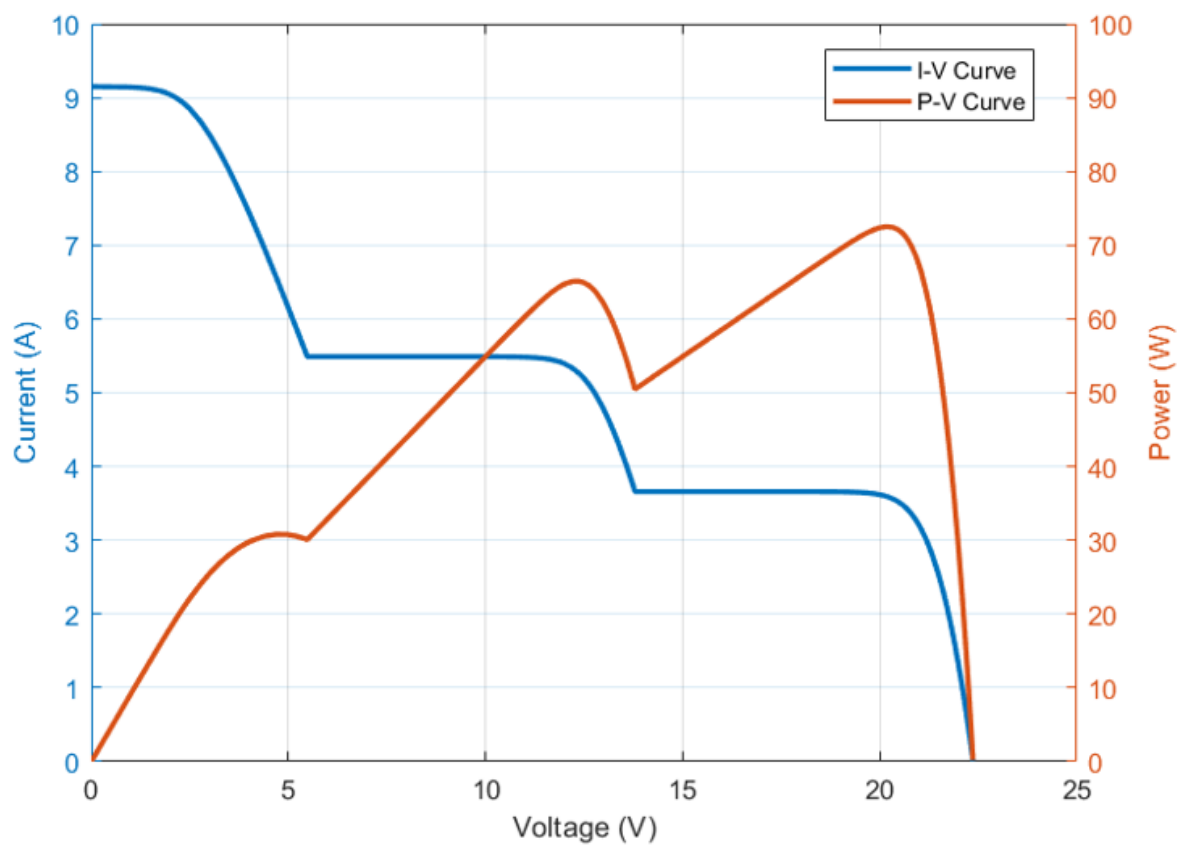

Figure 9. I-V and P-V curves of the solar array (shown in Fig 8) under partial shading.

\section{Assessment of Student Learning Outcomes:}

To assess impact on student learning outcomes, pre- and post-exercise quiz/surveys were conducted. Each quiz/survey included five technical questions (Q1 - Q5) for direct assessment and three non-technical questions (Q6 - Q8) to measure student perception on learning which were used as inputs for indirect assessment. Table 1 lists the technical questions (with the answer options and correct answer marked) in the quizzes used for direct assessment of learning outcome.

Table 1. Pre- and Post-Exercise Technical Questions for Direct Assessment

\begin{tabular}{|c|l|l|}
\hline Question \# & \multicolumn{1}{|c|}{ Question Statement } & \multicolumn{1}{c|}{ Answer Options } \\
\hline Q1 & Which of the following happens when series & $\square V_{o c}$ reduces \\
& resistance of a solar cell is increased? & $\square F$ reduces \\
& & $\square$ I am Not Sure \\
\hline Q2 & Which of the following happens when shunt & $\square V_{o c}$ reduces \\
& resistance of a solar cell is decreased? & $\square I_{S c}$ reduces \\
& & $\square$ I am Not Sure \\
\hline \multirow{2}{*}{ Q3 } & Which of the following happens when & $\square$ Output power increases \\
& temperature of a solar cell is increased? & $\square I_{S c}$ increases \\
& & $\square V_{o c}$ increases \\
& & $\square$ I am Not Sure \\
\hline
\end{tabular}




\begin{tabular}{|c|c|c|}
\hline Q4 & $\begin{array}{l}\text { Consider two solar cells }-\mathrm{C} 1 \text { and } \mathrm{C} 2 . \mathrm{C} 1 \text { has an } \\
\text { ideality factor of } 1.2 \text { and } \mathrm{C} 2 \text { has an ideality } \\
\text { Factor of } 1.6 \text {. All other parameters of the cells } \\
\text { are identical. Which of the following is correct? }\end{array}$ & $\begin{array}{l}\otimes C 1 \text { will have higher } F F \\
\square \text { C2 will have higher } F F \\
\square \text { C2 will output more power } \\
\square \text { I am Not Sure }\end{array}$ \\
\hline Q5 & $\begin{array}{l}\text { Which of the following happens when the } \\
\text { intensity of the incident sunlight on a solar cell is } \\
\text { doubled? }\end{array}$ & $\begin{array}{l}\square V_{o c} \text { is doubled } \\
\bigotimes I_{s c} \text { is doubled } \\
\square \text { Both } V_{o c} \text { and } I_{s c} \text { are doubled } \\
\square \text { I am Not Sure }\end{array}$ \\
\hline
\end{tabular}

Quiz/Surveys were voluntary and did not contribute to the final grade. Both pre- and post-exercise quizzes included exact same questions in the same order to ensure reliable data collection. Number of participants in the pre-exercise quiz/survey was 28 , whereas the total number of participants in post-exercise quiz/survey was 22 . The direct assessment result is graphically presented in Fig. 10, which compares the percentage of students getting correct answers for these five questions. It is evident that for all questions, there is a positive impact. For Q1 and Q2, the number of students getting the right answer increased more than two-fold. For Q2, there is about 50\% improvement in the percentage of correct answers. These results clearly indicate the substantial impact of the simulation exercises to enhance student learning.

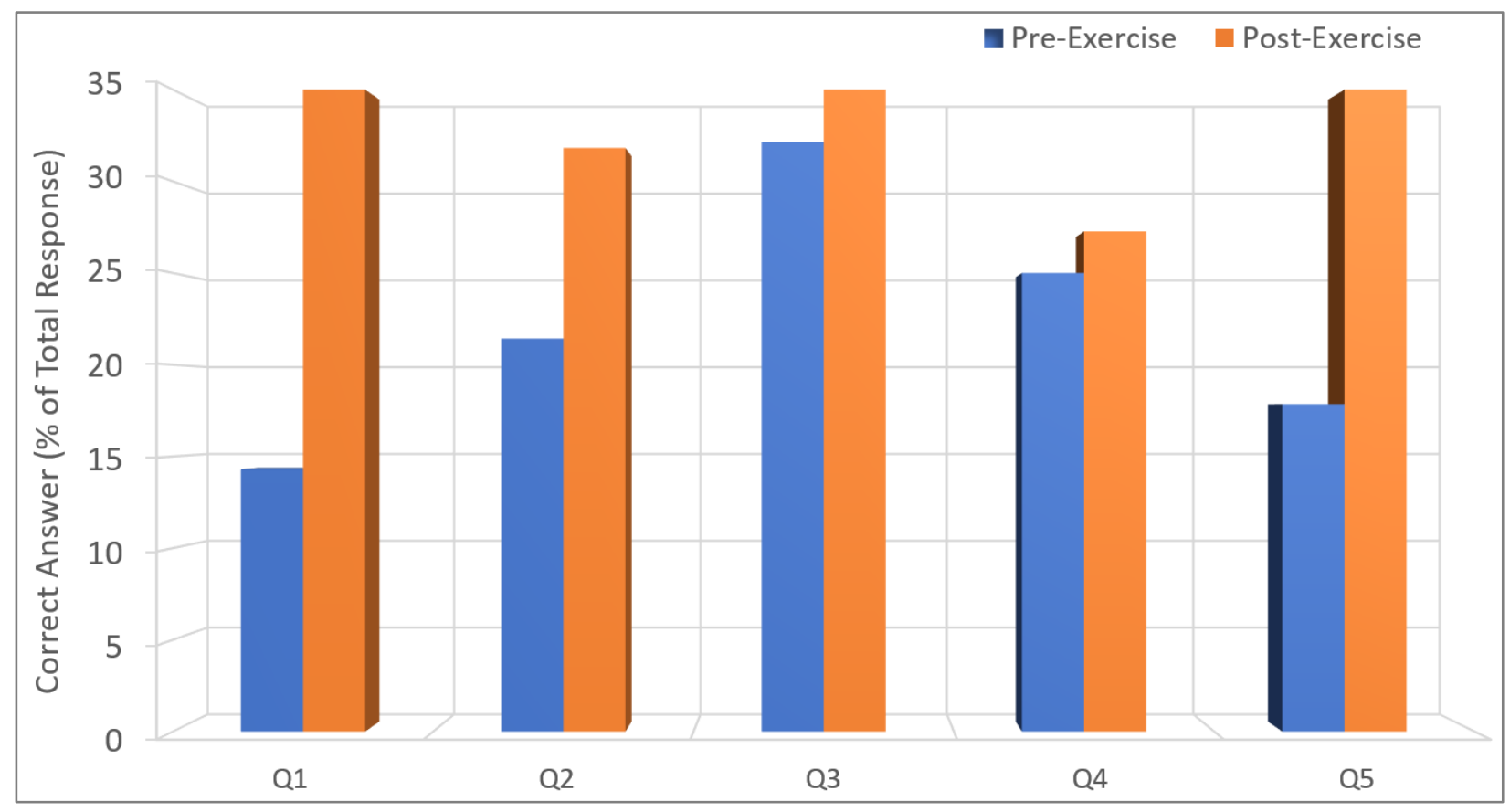

Figure 10. Student response to the technical questions.

In addition to direct assessment through quiz questions, three non-technical questions were asked to perform indirect measurement of learning outcomes. Table 2 lists the non-technical survey questions (with the answer options) used for passive assessment. For Q6, the assessment was based on the number of students who had a perception of 'Excellent' or 'Very good' understanding of solar cell characteristics and overall subject knowledge. Note that, these two boxes are marked in 
Table 2, which indicates that these two responses were considered as key impact assessment parameters. Similarly, for Q7 and Q8, the positive responses ('Strongly agree' and 'Somewhat agree') were selected as impact assessment parameters based on which the analysis were performed and results are presented in this paper.

Table 2. Pre- and Post-Exercise Survey Questions for Indirect Assessment of Student Learning

\begin{tabular}{|c|c|c|}
\hline Question \# & Question Statement & Answer Options \\
\hline Q6 & $\begin{array}{l}\text { Overall, at this point, my understanding and } \\
\text { knowledge level about the characteristics of } \\
\text { solar cells and modules can be considered as - }\end{array}$ & $\begin{array}{l}\otimes \text { Excellent } \\
\otimes \text { Very good } \\
\square \text { Average } \\
\square \text { Below average } \\
\square \text { Poor }\end{array}$ \\
\hline Q7 & $\begin{array}{l}\text { I understand how to use bypass diodes in solar } \\
\text { modules and arrays - }\end{array}$ & \multirow{2}{*}{$\begin{array}{l}\bigotimes \text { Strongly agree } \\
\bigotimes \text { Somewhat agree } \\
\square \text { Don't know } \\
\square \text { Somewhat disagree } \\
\square \text { Strongly Disagree }\end{array}$} \\
\hline Q8 & $\begin{array}{l}\text { I believe that simulation-based assignments are } \\
\text { more helpful to learn about solar cell behavior } \\
\text { than numerical problem based homeworks - }\end{array}$ & \\
\hline
\end{tabular}
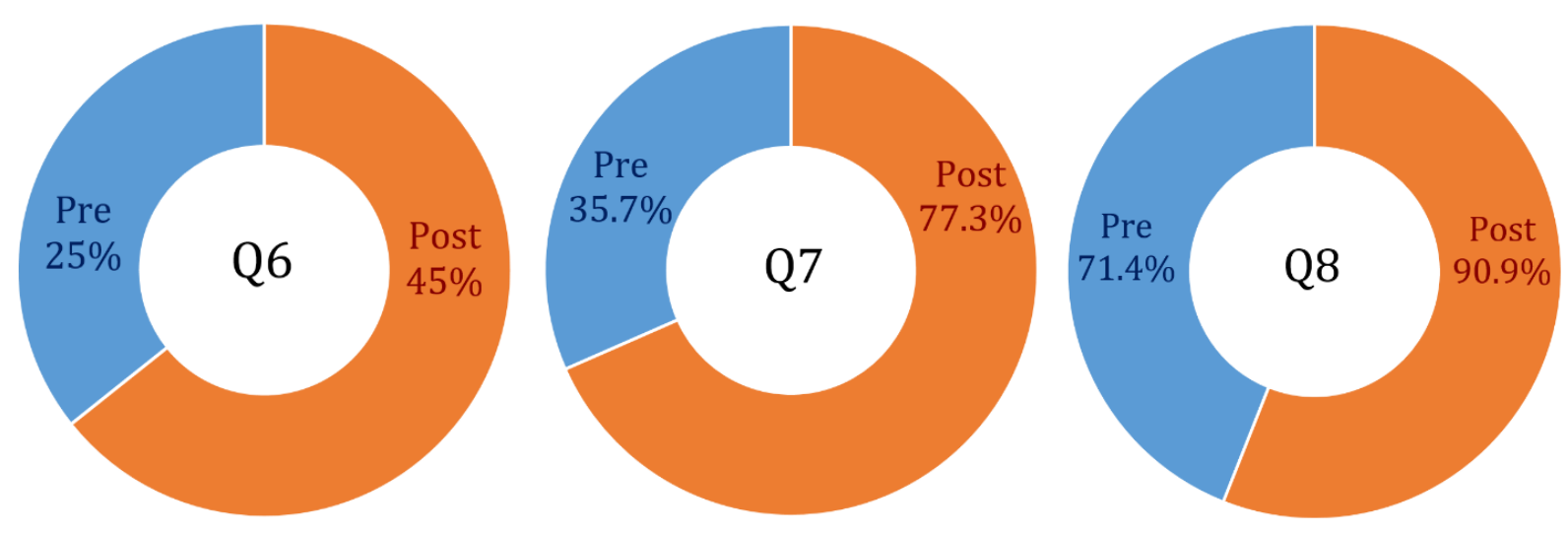

Figure 11. Student response to the technical questions.

The analyzed data is presented in Fig. 11, which shows the percentage of students responding to the key impact assessment parameters for Q6 - Q9. Clearly, the student perceptions on learning have improved substantially as indicated by the response to all three survey questions. Notably, a significant majority ( 91\%) of students recognized that simulation-based assignments helped more in learning solar cell behavior compared to other regular assignments based on numerical problems. The indirect assessment results support and strengthen the positive impacts observed by direct assessment. A future study is planned which will include more quiz questions which will contribute toward the final grades to ensure optimum effort and engagement of students while responding to the quiz questions. 


\section{Conclusions:}

MATLAB-Simulink based comprehensive simulation exercises were designed and implemented in an undergraduate level solar power course. Simulation exercises included important learning objectives including study of solar irradiance and temperature variation, effects of series and shunt resistances, analysis of I-V and P-V curves to extract PV performance parameters, designing PV modules, studying the effects of partial shading, and learn the use of bypass diodes. Both direct and indirect assessment technique were used to quantitatively measure student learning outcomes via pre- and post-exercise quizzes and surveys. Both direct and indirect measurements show strong improvements in all fronts of student learning outcomes - some achieved improvement factor more than $100 \%$. While learning outcomes improved after completion of the exercises, there is still many students not being able to answer correctly all the technical questions. It is concluded that improving the simulation tutorials, changing the mode of tutorial sessions from face-to-face to online sessions and changing the quizzes from voluntary to graded quizzes could help to further boost the learning outcomes and the direct assessment results.

\section{References:}

1. http://www.thesolarfoundation.org/national/

2. http://fortune.com/2017/02/07/us-solar-jobs-2016/

3. S. Das, K. C. Mandal, and R. N. Bhattacharya, "Earth-Abundant Cu2ZnSn(S,Se) 4 (CZTSSe) Solar Cells", Semiconductor Materials for Solar Photovoltaic Cells, Springer Series in Materials Science, Vol. 218, pp. 25-74, 2015 (ISBN: 978-3-319-20330-0).

4. S. Das, R. N. Bhattacharya, and K. C. Mandal, "Performance limiting factors of $\mathrm{Cu}_{2} \mathrm{ZnSn}\left(\mathrm{S}_{\mathrm{x}} \mathrm{Se}_{1-\mathrm{x}}\right)_{4}$ solar cells prepared by thermal evaporation", Solar Energy Materials and Solar Cells, Vol. 144, pp. 347-351, 2016.

5. S. Lineykin, M. Averbukh, and A. Kuperman, "An improved approach to extract the singlediode equivalent circuit parameters of a photovoltaic cell/panel", Renewable and Sustainable Energy Reviews, Vol. 30, pp. 282-289, 2014.

6. A. M. Humada, M. Hojabri, S. Mekhilef, and H. M. Hamada, "Solar cell parameters extraction based on single and double-diode models: A review", Renewable and Sustainable Energy Reviews, Vol. 56, pp. 494-509, 2016.

7. https://www.qcells.nl/uploads/tx_abdownloads/files/Hanwha_Q_CELLS_Data_sheet_Q6LMXP3G3_2013-04_Rev01_EN_08.pdf

8. P. Singh, N. M. Ravindra, "Temperature dependence of solar cell performance —an analysis", Solar Energy Materials and Solar Cells, vol. 101, pp. 36-45 (2012).

9. E. Cuce. P. M. Cuce, T. Bali, "An experimental analysis of illumination intensity and temperature dependency of photovoltaic cell parameters", Applied Energy, vol. 111, pp. 374382 (2013).

10. H. Patel, V. Aggarwal, "MATLAB-Based Modeling to Study the Effects of Partial Shading on PV Array Characteristics", IEEE Transactions on Energy Conversion, vol. 23, pp. 302310 (2008). 